\title{
A retrospective comparative study to evaluate the efficacy and safety of mifepristone with misoprostol over misoprostol alone in induction in labor
}

\author{
Reena Sharma, B. R. Sharma, Poojan Dogra*
}

Department of Obstetrics and Gynecology, SLBS GMC Mandi at Nerchowk, Himachal Pardesh, India

Received: 19 October 2018

Accepted: 13 November 2018

*Correspondence:

Dr. Poojan Dogra,

E-mail: poojandogramarwaha@gmail.com

Copyright: (c) the author(s), publisher and licensee Medip Academy. This is an open-access article distributed under the terms of the Creative Commons Attribution Non-Commercial License, which permits unrestricted non-commercial use, distribution, and reproduction in any medium, provided the original work is properly cited.

\begin{abstract}
Background: The aim is to compare the improvement in pre-induction Bishop's score, proportion of patients going in labor and induction-delivery interval after using the Misoprostol versus Mifepristone and Misoprostol as cervical ripening and labor inducing agent.

Methods: It is retrospective comparative study conducted on 110 women. Women were randomized in group A and in group B of 55 patients in each group. Group A received tab Mifepristone $200 \mathrm{mg}$ orally on day 1 followed by Misoprostol $25 \mathrm{ug}$ after 48 hours and continued 6 hourly till maximum four tablets and group B patients received tablet Misoprostol 25ug and continued 25ug 6hrly maximum 4 doses. Women observed for improvement in Bishop"s score, induction-delivery interval and requirement of subsequent doses of Misoprostol.

Results: Present study concluded that tablet Mifepristone is an efficient cervical ripening and inducing agent of labor as pre-induction Bishop's score was improved. 36.4\%patients went into labor only with tablet Mifepristone. The mean induction-delivery interval was, $19 \pm 12.2 \mathrm{hrs}$ in Group 1 as compare to $13.1 \pm 13.0 \mathrm{hrs}$ in Group 2. Mean Bishop's score observed in Group 1 were $2.5 \pm 1.78$ and $1.67 \pm 1.25$ in Group 2. It was observed that there was significant improvement in the Bishop's score after giving Mifepristone to the patients; mean Bishop's 24hrs after mifepristone were 4.03 \pm 1.80 . Repeated dose of Misoprostol required in Group 1 was observed to be higher than group 2 as shown in table 8. Mean misoprostol doses required in group 1 was $2.56 \pm 1.15$ as compared to $1.71 \pm 1.58$ in group 2 .

Conclusions: Mifepristone with Misoprostol reduce the induction delivery interval and more potent in combination for induction of labour as compared to Misoprostol alone.
\end{abstract}

Keywords: Bishop's score, Induction-delivery interval, Mifepristone, Misoprostol

\section{INTRODUCTION}

The progress of Medicine in general and of Obstetrics in particular has allowed for more high-risk pregnancies to evolve to term or close to term, with maternal or fetal pregnancy interruption before the onset of spontaneous labor.

This associated to the fact that vaginal delivery has become the best choice for women and health professionals have created the growing need to induce labor in women with unripe cervices. ${ }^{1}$ Induction should be considered when it is felt that the benefits of vaginal delivery outweigh the potential maternal and fetal risks of induction. These issues should be discussed with the woman prior to initiation of induction.

One of the most common indications for induction is post term pregnancy with a gestational age of at least 41 completed weeks. Induction for this indication has been shown to reduce the likelihood of perinatal death. ${ }^{2,3}$ Labor induction in unfavourable cervix conditions is a 
difficult and lengthy procedure, extenuating for both mother and obstetrician. Many times, it may fail and this outcome can be frustrating for both. Therefore, in the face of a situation indicating pregnancy interruption it is fundamental to assess the cervix conditions to predict induction success. Vaginal exam to assess the cervix may be an extremely subjective procedure and for this reason systematic methods to evaluate and standardize procedures in the case of need for cervical ripening and/or labor induction were created. Therefore, when labor induction

is performed, a favourable cervix is fundamental to a good outcome as well as an adequate cervical ripening procedure, when cervix is unripe.

Theoretically the ideal method for cervical ripening would be a non-invasive method causing the same physiological changes in the cervix, i.e. effacement and softening without uterine contractility compatible with active labor. ${ }^{4,5}$

Misoprostol is effective in ripening the cervix and hence can be used to induce as well as augment labor process. Tablet Mifepristone is also called as RU (Roussel Uclaf) - 486. It is 19- nor steroid with potent competitive ant progesterone and significant ant glucocorticoid activity. Mifepristone is used as a pretreatment to prime the cervix adequately. ${ }^{6}$

\section{METHODS}

It is a hospital based retrospective comparative study conducted on 110 women. with 55 cases in each study group, one under Misoprostol induction (GROUP1) and one under Mifepristone plus Misoprostol induction (GROUP 2) were done when admitted in the department of obstetrics and gynecology of SLBSGMCH Mandi at Nerchowk from 1st Jan 2018 to 31st July 2018. Women attending antenatal clinic, who met the inclusion criteria were enrolled in study. Written informed consent taken from patients.

All cases during the defined study period were recorded after retrieving data and a statistical analysis of various parameters- age, parity, and period of gestation and indication for caesarean section was done after gaining approval from the institutional ethics committee.

\section{Inclusion criteria}

- Over 40 weeks of gestation in live fetus.

- Singleton pregnancy.

- Cephalic presentation.

- Unfavorable cervix Bishop score $\leq 6$.

\section{Exclusion criteria}

- Pregnancy with any medical or surgical complication.
- Previous L.S.C.S.

- Mal - presentation.

- Congenital anomaly.

\section{Methodology}

After admission in ward, detailed history taken, general and systemic and obstetric examination was done to reassure lie, gestation age, and fetal heart rate. Per vaginal examination was done to assess Bishop's score and to assess pelvis. After basic investigations and workup the patients were selected for the study. After taking the Informed consent they are enrolled for the study.

Group 1 Patients consists of 55 patients. They received tablet Misoprostol $25 \mathrm{mcg}$ sublingual or oral and continued $25 \mathrm{mcg} 6$ hrly till patient went in active labor with maximum four tablets.

Group 2 Patients consists of 55 patients. In this group per vaginal examination of patient was conducted at the beginning of induction and Bishop's score was recorded. After administration of T. Mifepristone 200mg orally patient was not allowed to go home.

After 24 hrs repeat per vaginal examination done to note Bishop's score. They received T. Mifepristone 200mg orally on day 1 which is followed by T. Misoprostol 25 mcg sublingual or orally after 48 hrs and continued 6 hrly till patient goes in active labor with maximum four tablets.

After administration of drugs, vital signs of patients, fetal heart rate and signs of progress of labor were monitored at regular interval. Oxytocin augmentation and surgical ARM was done. if required. Checked for per vaginal bleeding or per vaginal leaking if present. FHR monitoring was done every $15 \mathrm{~min}$ in first stage of labor and every $5 \mathrm{~min}$ in second stage of labor to confirm fetal wellbeing. A per vaginum examination was done $4 \mathrm{hrly}$ in active labor to reassess Bishop's score. Uterine contractions were strictly monitored to see whether any uterine tachysystole or hypertonia was present.

Labour and delivery parameters including, interval from initiation of induction to delivery with misoprostol, mean number of doses of misoprostol until delivery, number of patients requiring oxytocin augmentation, mode of delivery were compared. Occurrence of side effects of drugs like fever, gastrointestinal symptoms, pain abdomen fainting were evaluated. Fetal criteria including presence of thick meconium in the amniotic fluid APGAR scores at one and five minutes, meconium aspiration, and transfer to NICU were also evaluated.

\section{RESULTS}

Table 1 is showing that the majority of women enrolled in both the group were from same age group (21-25); 
only $9.1 \%$ of patients were elderly (>30yrs) in both the groups.

Table 2 is showing that, in present study $89.5 \%$ of the patients with postdate pregnancy were induced with Misoprostol and $95.5 \%$ in group 2 respectively. All the patients were between 40-42 weeks in both the groups.
Table 3 is illustrating that the $49.1 \%$ of the patients were having bishop's score between $0-1$ in Group 1 and $69.1 \%$ of the patients in combination group were having Bishop's score 0-1when patients were admitted.

Mean Bishop's score observed in Group 1 were $2.5 \pm 1.78$ and $1.67 \pm 1.25$ in Group 2 .

Table 1: Distribution of patients by age.

\begin{tabular}{|lllll|}
\hline Age group (in years) & Number of cases Group & (Misoprostol) & $\begin{array}{l}\text { Number of cases Group 2 (Mifepristone }+ \\
\text { Misoprostol) }\end{array}$ \\
\hline$\leq 20$ & $\mathbf{N = 5 5}$ & $\mathbf{\%}$ & $\mathbf{N = 5 5}$ & $\mathbf{\%}$ \\
\hline $21-25$ & 4 & 7.3 & 12 & 21.8 \\
\hline $26-30$ & 32 & 58.2 & 23 & 41.8 \\
\hline $31-35$ & 14 & 25.5 & 15 & 27.3 \\
\hline$>35$ & 4 & 7.3 & 4 & 7.3 \\
\hline Mean \pm SD & 1 & 1.8 & 1 & 1.8 \\
\hline
\end{tabular}

Table 2: Distribution of patients according to gestational age in weeks.

\begin{tabular}{|c|c|c|c|c|}
\hline \multirow[t]{2}{*}{ Gestational age (weeks) } & \multicolumn{2}{|c|}{ Number of cases Group 1 (Misoprostol) } & \multicolumn{2}{|c|}{$\begin{array}{l}\text { Number of cases Group } 2 \text { (Mifepristone }+ \\
\text { Misoprostol }\end{array}$} \\
\hline & $\mathbf{N}=38$ & $\%$ & $\mathrm{~N}=\mathbf{2 2}$ & $\%$ \\
\hline $40-40.9$ & 34 & 89.5 & 21 & 95.5 \\
\hline $41-42$ & 4 & 10.5 & 1 & 4.5 \\
\hline$>42$ & 0 & 0.0 & 0 & 0 \\
\hline
\end{tabular}

Table 3: Bishop's score in both the groups when admitted.

\begin{tabular}{|c|c|c|c|c|}
\hline \multirow{2}{*}{ Bishop score } & \multicolumn{2}{|c|}{ Number of cases Group 1 (Misoprostol) } & \multicolumn{2}{|c|}{ Number of cases Group 2 (Mifepristone + Misoprostol } \\
\hline & $\mathbf{N}=\mathbf{5 5}$ & $\%$ & $\mathrm{~N}=55$ & $\%$ \\
\hline $0-1$ & 27 & 49.1 & 38 & 69.1 \\
\hline $2-3$ & 14 & 25.5 & 12 & 21.8 \\
\hline $4-5$ & 11 & 20.0 & 4 & 7.3 \\
\hline$>5$ & 3 & 5.5 & 1 & 1.8 \\
\hline Mean \pm SD & $2.5 \pm 1.78$ & & $1.67 \pm 1.25$ & \\
\hline
\end{tabular}

It was observed as per Table 4, that there was significant improvement in the Bishop's score after giving Mifepristone to the patients; mean Bishop's 24 hours after mifepristone were $4.03 \pm 1.80$.

In present study Table 5 illustrating that $18.2 \%$ of the patients required augmentation with Oxytocin in Group 2 where as $14.5 \%$ patients required augmentation in Group 1 which was expected in a course of labor.

Table 6 is illustrating that the $60 \%$ patients delivered within 20 hours of Misoprostol in Group 1; where $86 \%$ patients delivered within $12 \mathrm{hrs}$ in combination group where we used Mifepristone as pre-induction cervical ripening, which is proven not much significant with $\mathrm{p}$ value $=0.68$. Mean induction-delivery interval was more in Group 1 that was $19 \pm 12.2$ hours as compared to $13.1 \pm 13.0$ hours in Group 2. Table 7 is illustrating that $81.8 \%$ of patients delivered vaginally and $18.2 \%$ undergone caesarean section in Group 1 while $72.7 \%$ delivered vaginally and $23.6 \%$ undergo caesarean section in Group 2.

Repeated dose of Misoprostol required in Group 1 was observed to be higher than comparative group as shown in Table 8 . Noteworthy feature is $36.4 \%$ patients did not require even a single dose of Misoprostol after cervical ripening with Mifepristone suggesting that Mifepristone may be used only drug for induction. Mean doses of Misoprostol required in Group 1 was $2.56 \pm 1.15$ as compared to $1.71 \pm 1.58$ in Group 2 . 
Table 4: Bishop's score 24 hrs after giving Mifepristone in group 2.

\begin{tabular}{|llllll|}
\hline Bishop score & Mifepristone (Group 2) & Before 24 hours & Mifepristone + Misoprostol (Group 2) After 24 hours \\
\cline { 2 - 6 } & $\mathbf{N = 5 5}$ & $\mathbf{\%}$ & $\mathbf{N = 5 5}$ & $\mathbf{\%}$ \\
\hline $0-1$ & 38 & 69.1 & 3 & 5.5 & 23.6 \\
\hline $2-3$ & 12 & 21.8 & 13 & 29.1 & 9.1 \\
\hline $4-5$ & 4 & 7.3 & 16 & 32.7 \\
\hline$>5$ & 1 & 1.8 & 5 & 18 & \\
\hline Delivery & & & $4.03 \pm 1.80$ & \\
\hline Mean \pm SD & $1.67 \pm 1.25$ & & &
\end{tabular}

Table 5: Augmentation of labor required with oxytocin in both the groups.

\begin{tabular}{|lllll|}
\hline Augmentation of labour required & Group 1 (Misoprostol) & \multicolumn{2}{c|}{ Group 2 (Mifepristone + Misoprostol) } \\
\hline & $\mathbf{N = 5 5}$ & $\mathbf{\%}$ & $\mathbf{N = 5 5}$ & $\mathbf{\%}$ \\
\hline Oxytocin & 8 & $14.5 \%$ & 10 & $18.2 \%$ \\
\hline
\end{tabular}

Table 6: Induction delivery interval (hours) after first dose of Misoprostol between two groups.

\begin{tabular}{|lllll|}
$\begin{array}{l}\text { Induction delivery interval } \\
\text { after first dose of Misoprostol } \\
\text { (Hours) }\end{array}$ & Number of cases Group 1 & (Misoprostol) & $\begin{array}{l}\text { Number of cases Group 2 (Mifepristone } \\
\text { + Misoprostol) }\end{array}$ \\
\hline $\begin{array}{l}\text { Delivery } \\
\leq 10\end{array}$ & $\mathbf{N = 5 5}$ & $\mathbf{\%}$ & $\mathbf{N = 5 5}$ & $\mathbf{\%}$ \\
\hline $11-20$ & 16 & 29.1 & 18 & 32.7 \\
\hline $21-30$ & 17 & 30.9 & 29 & 18.7 \\
\hline$>30$ & 15 & 27.3 & 6 & 10.9 \\
\hline Mean \pm SD & 7 & 12.7 & 10 & 18.2 \\
\hline
\end{tabular}

Table 7: Mode of delivery in both groups.

\begin{tabular}{|lllll|}
\hline Mode of delivery & Group 1 (Misoprostol) & \multicolumn{2}{c|}{ Group 2 (Mifepristone + Misoprostol } \\
\hline NVD & $\mathbf{N}=\mathbf{5 5}$ & $\mathbf{\%}$ & $\mathbf{N = 5 5}$ & $\mathbf{\%}$ \\
\hline CS & 45 & 81.8 & 40 & 72.7 \\
\hline NVD + fcp & 10 & 18.2 & 13 & 23.6 \\
\hline
\end{tabular}

Table 8: Subsequent dosages of Misoprostol in both the groups.

\begin{tabular}{|lllll|}
\hline Dose of Misoprostol & Group & (Misoprostol) & Group 2 (Mifepristone + Misoprostol \\
\hline 0 & $\mathbf{N}=\mathbf{5 5}$ & $\mathbf{\%}$ & $\mathbf{N = 5 5}$ & $\mathbf{\%}$ \\
\hline 1 & 0 & 0.0 & 20 & 36.4 \\
\hline 2 & 10 & 18.2 & 6 & 10.9 \\
\hline 3 & 23 & 41.8 & 11 & 20.0 \\
\hline 4 & 3 & 5.5 & 6 & 10.9 \\
\hline Mean + SD & 19 & 34.5 & 12 & 21.8 \\
\hline
\end{tabular}

\section{DISCUSSION}

Mifepristone is an antiprogestogen that blocks the receptors for progesterones and glucocorticoids. It increases the sensitivity of the uterus to prostaglandins and facilitates labor. ${ }^{7}$ Tablet Mifepristone is also called as RU (Roussel Uclaf) - 486.It is 19 - nor steroid with potent competitive ant progesterone and significant ant glucocorticoid activity. Mifepristone is used as a pre- treatment to prime the cervix adequately. ${ }^{6}$ Present study concluded that there is significant improvement in Bishops score in group 2 ( $\mathrm{T}$. Mifepristone with $\mathrm{T}$. Misoprostol) compare with Group 1 (T. Misoprostol) this suggests that tab. Mifepristone act as cervical ripening agent and as well as labor inducing agent. Lil L et al found Bishops score was higher in women induced with T. Mifepristone. ${ }^{8}$ This drug causes reduction in induction -delivery interval also. In present study we observed 
mean IDI 13.1 \pm 13.0 hours in all cases after pre-induction cervical ripening with Mifepristone followed by misoprostol compared with the mean IDI $19 \pm 12.2$ hours with misoprostol only regimen. Elliot CL et al found in their conclusion that T. Mifepristone is known to cause softening and dilatation of cervix and increase in uterine activity. ${ }^{9}$

Mean Bishop's score observed in Group 1 were $2.5 \pm 1.78$ and 1.67 \pm 1.25 in Group 2. It was observed that there was significant improvement in the Bishop's score after giving Mifepristone to the patients; mean Bishop's 24 hours after mifepristone were $4.03 \pm 1.80$. Wing DA et al observed that the Bishop's score before administration of mifepristone were unfavorable $(<5)$ and almost $20 \%$ patients went in spontaneous labor with favorable Bishop's score $(>7)$ after administration of mifepristone. ${ }^{10}$ In present study $36.4 \%$ women went in labor and delivered only with T. Mifeprostone without misoprostol in group 2. Remaining 63.6\% Women required Misoprostol for induction of labor. Overall in group 2, 72.7\% had normal vaginal delivery, $3.6 \%$ had the forceps delivery and $23.6 \%$ underwent caesarean section. Su H et al states that $22.58 \%$ women went in labor without T. Misoprostol. ${ }^{11}$ The study done by Li L et al who found $80 \%$ delivered vaginally and $44 \%$ required caesarean section is comparable with present study. ${ }^{8}$ In group 2 rate of caesarean section was $23.6 \%$ higher as compared to in group 1 which was $18.2 \%$. J. Mcgill et al found rate of caesarean section was higher in women who required T. Mifepristone followed by T. Misoprostol which is comparable with present study. ${ }^{12}$

Repeated dose of Misoprostol required in Group 1 was observed to be higher than group 2 as shown in table 8 . Mean misoprostol doses required in group 1 was $2.56 \pm 1.15$ as compared to $1.71 \pm 1.58$ in group 2 . Noteworthy feature is $36.4 \%$ patients did not require even a single dose of Misoprostol after cervical ripening with Mifepristone suggesting that only Mifepristone may be used alone for induction of labor. In terms of requirement of subsequent repeat doses of misoprostol, maximum $41.8 \%$ of patients required at least 2 doses of misoprostol (25 microgram) in Group 1 as compared to $20 \%$ in group 2. The result of present study revealed that $\mathrm{T}$. Mifepristone is a simple, convenient, efficient and effective labor inducing agent in term pregnancy with poor Bishop's score as concluded by Li L et al.

\section{CONCLUSION}

Present study concluded that Mifepristone is an effective drug for cervical ripening and induction of labor when given 24 hours prior to misoprostol induction which decrease the need for prostaglandins and can be administered safely.
Funding: No funding sources

Conflict of interest: None declared

Ethical approval: The study was approved by the Institutional Ethics Committee

\section{REFERENCES}

1. Osis MJD, Padua KS, Duarte GA, Souza TR, Faúndes A. The opinion of Brazilian women regarding vaginal labor and cesarean section. Int $\mathbf{J}$ Obstet Gynecol 2001;75:S59-66.

2. Hannah ME, Hannah WJ, Hellman J, Hewson S, Milner R, Willan A. the Canadian Multicenter Postterm Pregnancy Trial Group: Induction of labour as compared with serial antenatal monitoring in postterm pregnancy. N Engl J Med. 1992;326(24):158792.

3. Crowley P. Interventions for preventing or improving the outcome of delivery at or beyond term (Cochrane Review). In: The Cochrane Library, Issue 3, 2000. Oxford: Update Software.

4. Bishop EH. Pelvic scoring for elective induction. Obstet Gynecol. 1964;24(2):266-8.

5. Mastrogiannis DS, Knuppel RA. Labor induced using methods that do not involve oxytocin. Clinical obstetrics and gynecology. 1995 Jun 1;38(2):259-66.

6. Frydman R, Baton C, Lelaidier C, Vial M, Bourget $\mathrm{P}$, Fernandez H. Mife prostone for induction of labour. Lancet.1991;337(8739):488-9.

7. Bygdeman M, Swahn ML. Progesterone receptor blockage, Effect on uterine contractility and early pregnancy. Contraception. 1985;32(1):45-51.

8. Li L, Gao W, Chen S. Labour induction in women at term with Mifepristone and Misoprostol. Zhoghua Fu Chan Ke Za Zhi. 1996;31(11):681-4.

9. Elliot CL, Brennand JE, Calder AA. The effects of Mifepristone on cervical ripening and labor induction in primigravidae. Obstet Gynecol. 1998;92(5):804-9.

10. Wing DA, Fassett Michael J, Mishell Daniel R, Mifepristone for Preinduction Cervical Ripening Beyond 41 Weeks' Gestation: A Randomized Controlled Trial, Obstet Gynecol. 2000;96(4):543-8.

11. $\mathrm{Su} \mathrm{H}, \mathrm{Li} \mathrm{E}$, Weng L. Mifepristone for labour induction. Zhonghua Fu Chan Ke Za Zhi.1996;31 (11):676-80.

12. J McGill, Shetty A. Mifepristone and Misoprostol in the induction of labour at term. Int $\mathrm{J}$ Gynaecol Obstet. 2007;96(2):80-4.

Cite this article as: Sharma $\mathrm{R}$, Sharma BR, Dogra P. A retrospective comparative study to evaluate the efficacy and safety of mifepristone with misoprostol over misoprostol alone in induction in labor. Int $\mathrm{J}$ Reprod Contracept Obstet Gynecol 2018;7:5140-4. 